\title{
A review of COVID-19 vaccines strategies and anti-vaxxers theories
}

\author{
${ }^{* 1}$ Adesokan, A., and ${ }^{2}$ Obeid, M. A. \\ ${ }^{1}$ PreciseMed, Glasgow, United Kingdom \\ ${ }^{2}$ Department of Pharmaceutics and Pharmaceutical Technology, Faculty of Pharmacy, \\ Yarmouk University Irbid, Jordan \\ *Correspondence to: Ade@precisemed.co.uk; dapoadesokan@gmail.com
}

\begin{abstract}
:
In what is a global record time of getting the COVID-19 vaccines available within 11 months, the world has equally been faced with several myths and conspiracy theories dissuading the public from accepting vaccination as an important measure in the response to the pandemic. We reviewed the leading conspiracy theories and balanced these with the scientific basis of viral transmission and replication and the broad role of vaccination in tackling this challenge. We briefly examined the design of the leading vaccines, and provided recommendations for worldwide COVID-19 distribution, acceptance and use.
\end{abstract}

Keywords: COVID-19, vaccine, anti-vaxxer, review

Received Feb 7, 2021; Revised Mar 11, 2021; Accepted Mar 12, 2021

Copyright 2021 AJCEM Open Access. This article is licensed and distributed under the terms of the Creative Commons Attrition 4.0 International License $<$ a rel="license" href="http://creativecommons.org/licenses/by/4.0/", which permits unrestricted use, distribution and reproduction in any medium, provided credit is given to the original author(s) and the source. Editor-in-Chief: Prof. S. S. Taiwo

\section{Un examen des stratégies de vaccins COVID-19 et des théories anti-vaxxers}

\author{
${ }^{* 1}$ Adesokan, A., et ${ }^{2}$ Obeid, M. A. \\ ${ }^{1}$ PreciseMed, Glasgow, Royaume-Uni \\ ${ }^{2}$ Department of Pharmaceutics and Pharmaceutical Technology, Faculty of Pharmacy, \\ Yarmouk University Irbid, Jordan \\ *Correspondance à: Ade@precisemed.co.uk; dapoadesokan@gmail.com
}

\begin{abstract}
Abstrait:
Dans ce qui est un temps record mondial pour obtenir les vaccins COVID-19 disponibles en 11 mois, le monde a également été confronté à plusieurs mythes et théories du complot dissuadant le public d'accepter la vaccination comme une mesure importante dans la réponse à la pandémie. Nous avons passé en revue les principales théories du complot et les avons équilibrées avec la base scientifique de la transmission et de la réplication virales et le rôle général de la vaccination dans la lutte contre ce défi. Nous avons brièvement examiné la conception des principaux vaccins et formulé des recommandations pour la distribution, l'acceptation et l'utilisation du COVID19 dans le monde.
\end{abstract}

Mots clés: COVID-19, vaccin, anti-vaxxer, revue

\section{Introduction:}

'The world hates change, yet it is the only thing that has brought progress' (1). 'Progress is impossible without change, and those who cannot change their minds, cannot change anything' (2). In 1882, the introduction of electricity was rejected. Several decades after Edison had formed the Edison Electric Illuminating Company of New York, most Americans still used gas lights and candles. In year 2020, anti-vaxxers are also doubting the science of the COVID vaccine and sponsoring theories to discredit its use. The social media is brimming with the unscientific personal opinions of a few political, community, and religious leaders asking their followers to reject the COVID-19 vaccine. One of the consequences of rejection of the efforts of researchers and drug-makers in terms of public health is the slowdown of coronavirus vaccination campaigns in countries where these false claims are deeply rooted.

This indirect effect of anti-vaxxers' 
influence may therefore weigh on mortality from coronavirus globally. This has apparently also downplayed the highly commendable feat accomplished in getting COVID-19 vaccines available within a record time of 11 months from when the first genome sequence of SARS-CoV-2 was made public and the emergence of the vaccines in December 2020. In this review, we briefly examined common conspiracy theories, and the design of the leading vaccines, and provided recommendations for acceptable worldwide COVID-19 vaccines distribution and use.

\section{Common COVID-19 conspiracy/ anti-vaxxer theories}

Pfizer/BioNTech and Moderna mRNA vaccines will alter human DNA

This theory is untrue. The messenger RNA (mRNA) vaccines cannot change human DNA as this is located and tucked away inside the nucleus. The nucleus is a small rounded area found close to the centre of human cells, with the cytoplasm in the periphery (Fig 1).

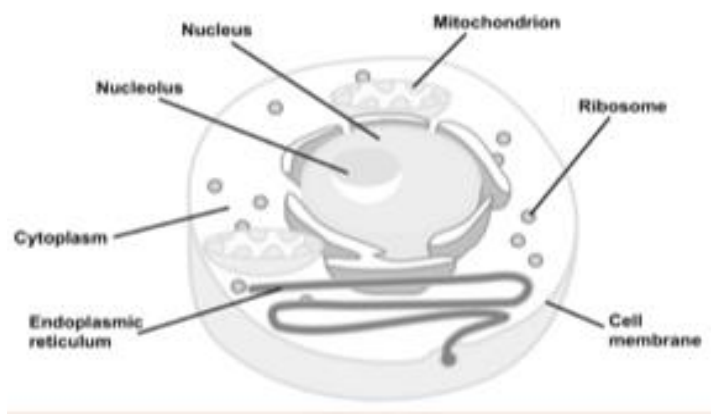

Fig 1: Human cell

To transport the vaccines into the cytoplasm, mRNA is enveloped in smart lipidmade layers called nanoparticles, where the mRNA is translated to spike proteins by a process known as ribosome processing (Fig 2).

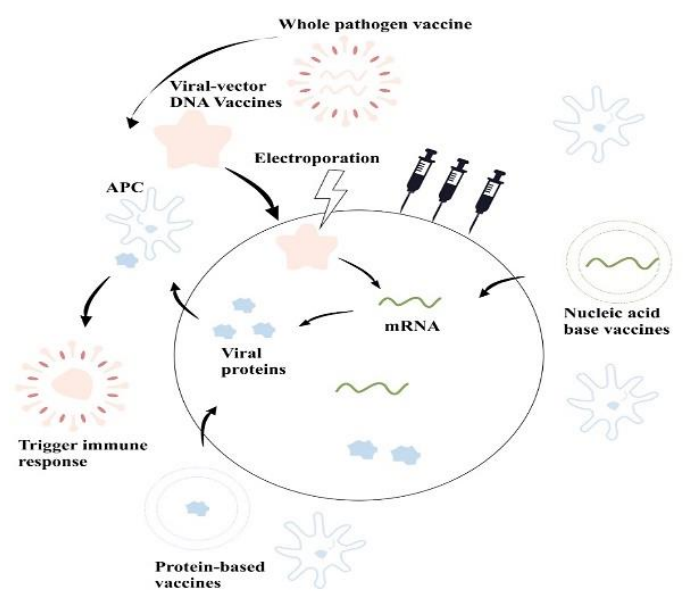

Fig 2: Virus vector DNA and mRNA vaccines' ribosome processing in cells after vaccination
This subsequently results in the SARS-COV-2 antigen presentation for the body's immune system to respond by making antibodies against the spike proteins needed to ward off future infections with COVID-19 virus after creating a $\mathrm{T}$ cell memory immune response. Therefore, the mRNA molecules cannot penetrate the nucleus to reach the DNA and alter it as widely acclaimed by the social media conspiracy theorists. It is also not possible for these mRNA vaccines to integrate into the host genome (3).

New vaccine's DNA would form chimers Conspiracy theorists believe that the new vaccine causes a mixture between animal and viral DNA and the human DNA to form a chimera i. e. a single organism having cells with more than one genotype. In the real sense, the human DNA is already a natural form of chimera which is made of DNA of endogenous retroviruses and other inherent animal species. Thus, no new chimera is formed after the vaccine is given to a person.

\section{Vaccines created to reduce Africa's population} This is particularly a major issue among people of African descent in general. In 2021, there is a higher level of ethical requirements and transparency about human subjects in clinical trials, drug safety policies, and vaccine formulation processes before they are used for disease prevention among the general public. The conspiracy theory which suggests that the newly approved COVID-19 vaccines have been created to decimate the Africa's population is not true. What is true is the fact that neither Pfizer plant which are located in Puurs, Belgium, or Michigan in the US nor the Lonza Moderna's factory plant in the Swiss Alps have been primed to make a segregated vaccine for Africa alone.

What is needed to complement the use of the current vaccines would be for researchers in Africa to gather scientific data through polymerase chain reaction (PCR) assays, genomics, and antibody tests, to tell the African's story about COVID-19. Such objectivity would lay the premise for evidencebased vaccine protocols that would attests to the required dose and timing of vaccination to achieve herd immunity peculiar to Africa.

Metals and toxins in vaccines are capable of human $5 \mathrm{G}$ radiation susceptibility

The ingredients in the vaccines as listed by the manufacturers show no metallic contents that could be toxins or cause human to be susceptible to $5 \mathrm{G}$ radiations. The only metals in vaccines are found in the buffer salts with neutral charges in salt, their quantities are too inconsequential to mount such false claim effects. 


\section{Religious theories}

A number of Christians view the Bill and Melinda Gates patent 060606 as the technology carrying the microchips that will also emblem the lipid nanoparticles in the COVID-19 vaccines. It is believed that the recipients of the COVID-19 vaccine potentially have the mark of the anti-Christ that will be used as cryptocurrency for the future. From scientific point of view, the nanoparticles used in the preparation of vaccines definitely do not carry microchips.

Nanoparticles are mere carriers or vehicles to convey and protect the genetic information as they travel to the target cells (6). Several other medications use nanoparticles technology right now and their use will increase more because of their effectiveness in delivery medications to targeted sites without collateral damages to unrelated sites or organs (7-9).

Ionizable cationic lipids, phospholipids, cholesterol, and polyethylene glycol (PEG)-lipids are the main constituents of lipid nanoparticles (LNP) (Fig 3). Each component is responsible for payload protection, and enables effective intracellular delivery. Ionizable cationic lipids are fundamental drivers for nucleic acid entrapment, and determine the potency for intracellular delivery (10).

Nanoparticles may be referred to as smart-nanoparticles but they cannot be considered as microchips. In the Pfizer and Moderna vaccines, these nanoparticles are composed of lipids, most of them originally present in human cytoplasmic membranes and are serving as carriers to merely transport mRNA in the case of COVID-19 vaccines to target cells cytoplasm (11).

\section{Box 1: Vaccine contents}

Pfizer covid-19 vaccine: "Each dose has mRNA, lipids (4-hydroxybutyl) azanediyl) bis (hexane-6, 1-diyl) bis (2-hexyldecanoate), 2 [(polyethylene glycol)-2000]-N, N-ditetradecylacetamide, 1, 2-Distearoyl-sn-glycero-3phosphocholine, and cholesterol), potassium chloride, monobasic potassium phosphate, sodium chloride, dibasic sodium phosphate dihydrate, and sucrose" (4).

Moderna COVID-19 vaccine: "Each dose has a total lipid content of $1.93 \mathrm{mg}$ (SM-102, polyethylene glycol [PEG] 2000 dimyristoyl glycerol [DMG], cholesterol, and 1,2-distearoyl-sn-glycero-3-phosphocholine [DSP C]), $0.31 \mathrm{mg}$ tromethamine, $1.18 \mathrm{mg}$ tromethamine hydrochloride, $0.043 \mathrm{mg}$ acetic acid, $0.12 \mathrm{mg}$ sodium acetate, and $43.5 \mathrm{mg}$ sucrose" (5).

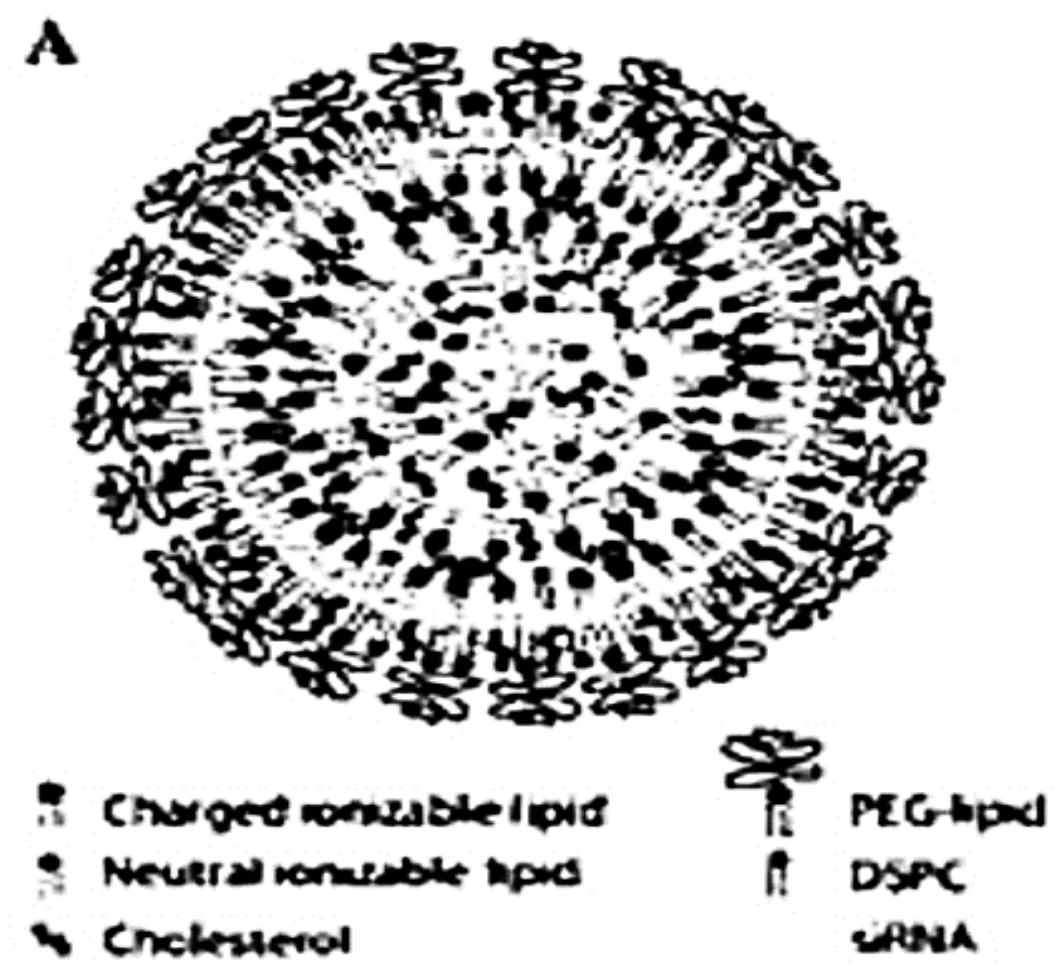

Fig 3: Structure and Internal morphology of lipid nanoparticles containing siRNA 
Meanwhile, some Muslims believe vaccines could be a form of 'halal' because of their usefulness in protecting humans from serious infections and diseases (12). Furthermore, because some of these vaccines are made from components that were originally 'halal', Pfizer and Moderna vaccines could be named 'halal vaccines' if declared to be so, based on fatwa i. e. a ruling on a point of Islamic law given by a recognized authority. Malaysia is currently conducting such a ruling on the COVID-19 vaccines.

Many scriptural references are in support of medicinal approaches to preventing and curing diseases or sicknesses (13). For example, Biblical and Hebrew healings have some of their bases and roots in natural elements such as balm, earth (dirt), oil, and salt.

\section{Luciferase technology use on COVID-19 vaccinated persons \\ Infrared scanners and Luciferase} technology are typically used to verify if an individual has had previous measles vaccination. It is based on ability to exhibit bioluminescence. There is no evidence to support that the current COVID-19 vaccines exhibit such bioluminescence technology. No approval has been granted to use luciferase technology on COVID-19 vaccinated patients. What is being advocated is a COVID-19 vaccine passport for travel and other verification purposes.

\section{COVID-19 vaccines}

Traditionally, whole pathogen vaccine contains the virus or bacteria that cause the disease in a subdued form. Measles vaccine for example contains measles virus, and $\mathrm{Hib}$ vaccine contains Haemophilus influenza type $b$ bacteria. There are two ways to make whole pathogen vaccines; the microbes are either deactivated (weakened) or exterminated (killed) to the point that they cannot make a person receiving the vaccine sick.

Vaccines work by stimulating the immune system to produce antibodies, exactly like it would if exposed to the disease-causing pathogen. After being vaccinated, the individual is expected to develop immunity to that disease such that should the vaccinated individual be exposed to the disease again, $\mathrm{s} /$ he would not suffer severe disease. The current COVID-19 vaccines in addition to this traditional approach utilised nucleic acid, viral vector, protein-based approaches to make current candidate vaccines.

\section{Pfizer-BioNTech vaccine}

The vaccines from Pfizer and Moderna both work in the same way. The two vaccines use the tiny snippets of human genetic code, called mRNA, to prompt the immune system into producing antibodies to the coronavirus. These are the first such vaccines to be authorized for use.

\section{Moderna vaccine}

Moderna vaccines like Pfizer-BioNTech are made from nucleic acids (mRNA) that are encapsulated into lipid nanoparticles prepared from mainly phospholipids and cholesterol. The synthetic phospholipids used in the process resemble the natural phospholipids found in the human cells.

\section{Oxford/AstraZeneca vaccine}

The Oxford/AstraZeneca vaccine is another coronavirus vaccine, but differs in its preparation when compared with the Pfizer and Moderna vaccines. The Oxford/AstraZeneca vaccine has its roots in the adenovirus-5, a virus taken from Chimpanzee. During the vaccine formulation, the adenovirus- 5 in a virus vector capsid is genetically modified to transport genetic information in form of virus DNA to the human cells for the subsequent translation to produce spike proteins (Fig 2). Spike proteins are the distinguishing feature of the corona virus. Upon vaccination, it is expected that the human cells will start to produce the spike proteins and the spike proteins will lead to the generation of antibodies against these spike proteins to confer immunity against the coronavirus.

\section{Efficacy of the approved vaccines}

As emergency use authorization (EUA) approvals continue to roll out throughout the world, the United Kingdom, Bahrain, Mexico, Saudi Arabia were trail blazers granting early authorizations for the use of the Pfizer BioNTech COVID-19 vaccine in their countries. Moderna vaccine was first granted emergency use authorization (EUA) in the United States. The first shot of the Moderna vaccine confers $50 \%$ protection against the risk of developing severe COVID-19. The second dose, scheduled to be taken 28 days later, increases vaccine effectiveness to $94.1 \%$. The Pfizer BioNTech COVID-19 vaccine first shot confers $52 \%$ protection against mild to severe disease, with the second dose taken after 21 days, offering up to $95 \%$ effectiveness (17). 


\begin{abstract}
Box 2: Development of mRNA vaccines
Messenger RNA (mRNA) was discovered and announced with fun fare as the foundation towards new vaccines and drugs development in 1961. For decades, the efforts and contributions mRNA therapeutics by Katalin Karikó, a biochemist at the University of Pennsylvania was not given its due regards (14). Adjunct Associate Professor Karikó researched extensively the technology to use mRNA as life's building block in creating a new set of therapeutic agents in form of vaccines and drugs for unmet clinical needs. Karikó was one of the first to understand the concept of using mRNA molecules copy instructions from DNA in the cell nucleus, and transport them to the cytoplasm for ribosome processing to make vital therapeutic proteins.
\end{abstract}

\title{
Nanoparticles-driven vaccine development process
}

In a Petri dish, artificial mRNAs are made and transported in nanoparticles to cytoplasm' ribosomes of human cells to make therapeutic proteins, corona spike proteins in the case of COVID-19 vaccines. These proteins presented as antigens to our immune system to generate specific antibodies to fight off a future exposure to the same virus should the vaccinated person become exposed again to the virus.

\section{Emergence of PCR}

In 1984, the polymerase chain reaction (PCR), was invented by the American biochemist, Kary Mullis (15). PCR was designed to amplify very small amounts of DNA, thus in vast use in genetics, genomics, crimes investigation etc. Few years down the lane, other life science researchers joined the train of creating catalytic actions of RNA polymerase enzyme to create mRNA molecules, thus generating mRNA from PCR by amplifying and multiplying DNA strands.

\section{Fatal immune response obstacle}

For years, studies on use of the artificial mRNA stopped because of the severe inflammatory reactions on the test animals. To overcome this obstacle, Karikó collaborated with Drew Weissman, a respected immunologist (now a Professor of Infectious Diseases in Penn's Perelman School of Medicine). They forged ahead when they created a form of mRNA incapable of provoking the immune system after Karikó discovered that uridine of the RNA's genetic code could trigger certain immune receptors likely causing the fatal immune response.

\section{The success of 2005 led to today's mRNA vaccines}

In 2005, Karikó and Weissman published a study replacing uridine to generate a specifically modified form of mRNA, which led to a non-fatal immune response (16). More extensive studies with the mice injected with this modified mRNA revealed a non-fatal immune response as the mice in the study survived. In 2010, Derrick Rossi co-founded a biotech company called Moderna, with the goal of this using modified mRNA to create vaccines and therapeutics on the premise of the study published by Karikó and Weissman. Using this technology, Moderna initially developed a potential Zika and Influenza vaccines. Therefore, when COVID-19 emerged, the company rode on this success story to develop their versions of COVID-19 mRNA vaccines. In 2020 these mRNA-based vaccines; Moderna's showed 94\% efficacy, while Pfizer-BioNTech revealed 95\% efficacy in a Phase III clinical trial.

\section{Side effects or adverse events post-vaccination}

In clinical use round the world, the common side effects reported post vaccination typically are fever, injection site redness and pain. Others are itching, diarrhoea, vomiting, lethargy, muscle aches, headache, vertigo, and dizziness. These symptoms are usually worse after second dose and during the last few days. Pfizer BioNTech, Moderna, AstraZeneca have put in place post-vaccination pharmacovigilance and other safety surveillance systems in their bid to monitor the potential reactions that people might develop after taking these vaccines.

In the post-approval vaccination with Pfizer BioNTech vaccine, a few health workers in the UK were reported to have developed anaphylaxis. Anaphylactic reactions to vaccinations usually occur in people with preexisting allergies or multiple allergies to any or all of the ingredients used in preparing the vaccines. In the light of this, the recommendation is for individuals prior to receiving vaccinations to answer all allergy questions truthfully. Users are expected to check the lists of ingredients in the vaccine and do not proceed if any known allergy is stated. It is recommended that individuals with multiple allergies are cautious while considering taking the Pfizer/ BioNTech vaccination.

The COVID-19 vaccines would be reviewed in due course to correctly ascertain if it poses some risks of birth defects to expectant mothers because the trials did not include pregnant or lactating women. It is worthy to note that according to UK gov.uk website (18), the safety and efficacy of the COVID-19 mRNA vaccine BNT162b2 in children under 16 years of age have not yet been established.

\section{Importance of T-cell tests post- vaccination}

T-cells originate from stem cells in the bone marrow. As they develop, they migrate to the thymus gland, hence their name " $T$ " cells. In the thymus, they display antigens that are eliminated down to those that recognize self. Antigens distinguish subtypes; 
CD4+ $\mathrm{T}$ cells (helper $\mathrm{T}$ cell) recognize foreign antigens on macrophages, stimulate $B$ cells to produce antibodies, secrete cytokines, and activate $\mathrm{CD}^{+} \mathrm{T}$ cells (cytotoxic $\mathrm{T}$ lymphocytes or CTLs). $\mathrm{CD}^{+} \mathrm{T}$ functions to burst virallyinfected cells.

In COVID-19, $T$ cells appear a day or two after symptoms start; they bind the virus at several sites, and persist. Tracking $\mathrm{CD}^{+} \mathrm{T}$ cells in recovered COVID-19 patients or post vaccination of individuals using investigative longitudinal studies, can help to ascertain if memory $\mathrm{CD}^{+} \mathrm{T}$ cell response is sustained for an extended period. This would help to ascertain whether the current 6 months dosing vaccination regimen should be sustained long term.

A cohort study (19) revealed that out of 94 patients with blood COVID-19 antibodies tested during a follow-up study reported an initial seropositivity rate of $96 \cdot 2 \%$ which later declined to $58.5 \%$ after 6 months. Likewise, the median titres of the neutralising antibodies dropped from 19.0 in the acute phase to 10.0 after 180 days. This is likely to be the reason for reported incidence of reinfection in patients after 5-6 months seen in some previously infected COVID-19 patients worldwide.

\section{Discussion}

The long-term safety data on the COVID-19 vaccine is not available at the moment. Readers and users of the vaccines may rely on the great knowledge and advances that have materialized in the field of science and on the vaccine platforms. Credits go to remarkable and resilient Moderna researchers such as Kanika Karikó in collaboration with Weissman and in the UK, Professor Sarah Gilbert, the brainchild of AstraZeneca Oxford Vaccine.

From 8 days after receiving the 1 st shot to ten weeks post $2^{\text {nd }}$ dose vaccination, scientists would be eager to know whether initial immune response has been conferred, and studies are on ongoing on the Pfizer vaccine in Israel to answer these questions. In the coming months further down the lane, Immunologists are expected to perform complex T-cell tests to study T-cell memory vaccine-generated response to the spike proteins and how long lived the B-cell antibody production to these vaccine-induced spike proteins would be. It is expected that if individuals previously vaccinated become infected with SARS-COV-2, the effect would only be a mild or asymptomatic course of COVID-19 disease.

Scientists would also want to know whether sufficient anti-nucleocapsid IgG antibody and anti-coronavirus spike antibody titres produced in response to the vaccination are sustainable long enough to get a patient through the long pandemic haul. It is at the moment uncertain if several multiple doses would be needed at intervals to build a sustained immunity.

The news of the expedited clinical trials of Oxford/AstraZeneca vaccine which began in April 2020 and approved for clinical patient use by $30^{\text {th }}$ of December 2020 is refreshing in the space of life sciences in the UK. The approval granted though quick did not sacrifice the integrity and safety of the vaccine science. Furthermore, everything about the Oxford vaccine is a plus; the cost, storage, UKmade, and 100 million doses available for the UK population. The question now is how long before the herd immunity becomes a reality all over the world.

\section{Vaccine distribution, availability and storage issues}

Beyond hoarding toilet paper in 2020 is the challenge of effective and safe storage for vaccine in 2021 worldwide. Recommended temperature for Pfizer BioNTech vaccines is $-80^{\circ} \mathrm{C}$, while the Moderna vaccines is $-20^{\circ} \mathrm{C}$. Distribution and safe storage conditions are expected to be the major obstacles in Africa, South America, and South East Asia.

\section{Conclusions:}

The world has suffered a significant amount of physical, emotional, and financial losses from dealing with the unforeseen challenges of COVID-19. At the time of writing this article, more than 84 million confirmed cases with close to 1.84 million deaths have been recorded worldwide as at $3^{\text {rd }}$ of January 2020 (20). A review of echocardiograms of 1,261 patients from 69 countries by researchers at Edinburgh University revealed abnormal scans for more than half of hospitalized COVID-19 patients; 55\% of the patients in the study had abnormality in the pumping function of the heart, with one in seven showing evidence of severe dysfunction (21). Another study showed that $29.4 \%$ of 47,780 COVID-19 patients who needed inpatient hospital treatment were readmitted within 140 days after the initial discharge home, with one in ten $(12.3 \%)$ during the readmission being elderly (over 65 years of age), and Black, Asian and Minority Ethnic (BAME) backgrounds had the highest readmission rates (22). These data attest to the devastating cardiovascular effects of COVID19 among the BAME elderly and the need for an immediate use of vaccination for rescue.

With the arrival of Pfizer, AstraZeneca, Moderna and other candidate vaccines, the uncertainties and questions around the world are; how long will the pandemic last? should I get the vaccines? what will our lives look like 
when the pandemic is over? could I still be infected post vaccination in the light of the fact that frontline health workers in the US and UK have been reported to develop severe COVID19 , a month after receiving vaccination? Should this happen there is no need to panic, as it is estimated to take 8 days after $1^{\text {st }}$ dose to 10 weeks of $2^{\text {nd }}$ dose post vaccination for the much-desired immunity the vaccine confers to reach climax. Therefore, responsible citizens should continue with stringent measures to slow down the spread of SARSCoV-2, the virus that causes COVID-19. This means the wearing of facemasks, frequent handwashing, avoiding large gatherings or crowds and practicing social distancing. The take-home message is not rest on your oars despite the emergence of the new COVID-19 vaccines.

This review is an attempt to address the doomsday conspiracy theories offered by poorly-informed social media anti-vaxxers who may have a large listening audience in less developed countries of the world. Antivaccination has been around a long time, such as anti-fertility and anti-tetanus toxoid vaccines which have had severe impact on the willingness of people to take life-saving vaccines. There is therefore the need to debunk such outrageous claims and get the world in one voice to support scientists and researchers so that collectively we may retrace our footsteps and get our normal lives back.

\section{Acknowledgements:}

PreciseMed is a bespoke drug development research company based in Scotland with special interests in developing topical, oral, nebulised and parenteral formulations for unmet clinical needs mainly as delivered in organ-targeted nanoparticles to reduce systemic toxicity and optimise efficacy, as well as conduct specialised preclinical studies and clinical trials on novel therapies.

\section{Funding:}

\section{Authors received no public funds}

\section{Authorship contributions:}

Dr Adesokan wrote the science and medical aspects of COVID-19 vaccines while Dr Obeid wrote the nanotechnology aspect.

\section{Competing interests:}

Authors declare no conflict of interest

\section{References:}

1. The Washington Post The world hates innovation; this is why. July $21^{\text {st }} 2016$

2. Shaw, B. Creed and Conduct, Everybody's
Political What's What? London: Constable and Co. 1944

3. Naik, R., and Peden, K. Regulatory considerations on the development of mRNA vaccines. Curr Top Microbiol Immunol. 2020.

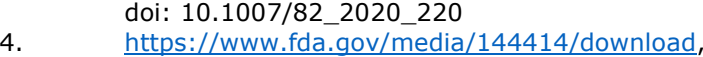
P.B.v., 2020

5. https://www.fda.gov/media/144638/download, M.v., 2020.

6. Obeid, M. A., Rothwelle, J., T., Mullen, A., B., and Ferro, V. A. In Grumezescu, A. M. (ed.). Lipid Nanocarriers for Drug Targeting. Elsevier. 2018: 313-359.https://doi.org/10.1016/B978-0-12813687-4.00008-6

7. Lamberti, G., and Barba, A. A. Drug Delivery of siRNA Therapeutics. Pharmaceutics. 2020; 12: 178.doi:10.3390/pharmaceutics 12020178

8. Constantinescu, C. A., Fuior E. V., Rebleanu, D., et al. Targeted transfection using PEGylated cationic liposomes directed towards P-selectin increases siRNA delivery into activated endothelial cells. Pharmaceutics. 2019; 11 (1): 47.

9. Obeid, M. A., Rothwelle, J., T., Dufes, C., Somani, S., Mullen, A., B., and Ferro, V.A. Proof of concept studies for siRNA delivery by non-ionic surfactant vesicles: invitro and invivo evaluation of protein knockdown. J Liposome Res. 2019; 29 (3): 229238.doi:10.1080/08982104.2018.1531424

10. Kulkarni, J. A., Mercer, J. E., Evers, M. J. W., et al. State-of-the-Art Design and Rapid-Mixing Production Techniques of Lipid Nanoparticles for Nucleic Acid Delivery. Small Methods. 2018; 2: https://doi.org/10.1002/smtd.201700375

11. Van Hoogevest, P., and Wendel, A. The use of natural and synthetic phospholipids as pharmaceutical excipients. Euro J Lipid Sci Technol. 2014; 116 (9): 1088-1107.

12. Musharraf Hussain, M. The Majestic Quran, June 2020. Quran 10: 57; Quran 16: 69; Quran 17: 82: Quran 26: 78-80 and Quran 41: 44. Holy Bible, New International Version (NIV) Copyright (C)1973, 1978, 1984, 2011. 2 Kings 2:21; 2 Kings 20:7; Genesis 2:9, Ezekiel 47:7, 12; and Revelation 22:2.

14. Cox, D. How mRNA went from a scientific backwater to a pandemic crusher. Health. Published December $\quad 2^{\text {nd }} 2020$. https://www.wired.co.uk/article/mrnacoronavirus-vaccine-pfizer-biontech

15. Mullis, K. B. The Unusual Origin of the Polymerase Chain Reaction. Scientific American. 1990; 262 (4): 56-65

16. Karikó, K., Weissman, D., Ni, H., and Buckstein, M. Suppression of RNA Recognition by Toll-like Receptors: The Impact of Nucleoside Modification and the Evolutionary Origin of RNA. Immunity. 2005; 23 (2): 165-175.

17. Polack, F. P., Thomas, S. J., Kitchin, N., et al., Safety and 'Efficacy of the BNT162b2 mRNA COVID-19 Vaccine. NEJM. 2020; 383: 2603-2615 Gov.uk Report. Information for Healthcare Professionals on Pfizer/BioNTech COVID-19 vaccine. Updated 30 December 2020.

19. Chaolin, $\mathrm{H}$., Lixue, $\mathrm{H}$., Yeming, W., et al. 6-month consequences of COVID-19 in patients discharged from hospital: a cohort study. The Lancet. 2021; 397: 220-232

20. World Health Organization (WHO) Coronavirus Disease (COVID-19) Dashboard Data. Last updated: 2021/1/3, 10:38pm CET

21. Dweck, M. R., Bularga, A., Hahn, R. T., et al. Global evaluation of echocardiography in patients with COVID-19. European Heart Journal Cardiovascular Imaging. 2020; 21 (9): 949-958. https://doi.org/10.1093/ehjci/jeaa178

22. Ayoubkhani, D., Khunti, K., Nafilyan, V., et al. Epidemiology of post-COVID syndrome following hospitalisation with coronavirus: a retrospective cohort study. Preprints medRxiv; Posted January $15,2021$. 